\title{
Budidaya Organik Kunyit pada Kluster Biofarmaka Kabupaten Karanganyar
}

\author{
Samanhudi*, Ahmad Yunus, Bambang Pujiasmanto \\ Program Studi Agroteknologi, Fakultas Pertanian, Universitas Sebelas Maret \\ *Corresponding author: samanhudi@staff.uns.ac.id
}

\begin{abstract}
Potential development of medicinal plants in Karanganyar is very large, because this area is famous as a center of medicinal plants such as ginger, turmeric, kencur, and temulawak. In the development of medicinal plants, the approach of organic cultivation is one of the alternatives that can be done to achieve the business. Therefore the application of technology to society about organic farming on Biopharmaca Cluster of Karanganyar was conducted with the aim to apply organic cultivation techniques that have resulted from previous studies, so it can be applied by the community to increase income and welfare. This application of technology to society activity is held in Sambirejo, Jumantono, Karanganyar. The research was conducted from March to October 2016. The results showed that the application of chicken manure affects the number of leaves, number of tillers, and the fresh weight of turmeric rhizome. The addition of manure (chicken, goat, cow) can increase all variables of planting growth which include plant height, number of leaf, number of tillers, fresh weight of plant, dry weight of plant, and fresh weight of rhizomes. Giving three types of manure (chicken, goat, cow) with mycorrhizal dose treatment there is no intraction to some growth observation variables. Mycorrhizal treatment with a dose of $10 \mathrm{~g} /$ plant can increase the number of tillers in turmeric. Overall the application of mycorrhizal at various doses $(5,10$, and $15 \mathrm{~g} /$ plant) can increase plant height, leaf number, number of tillers, and fresh weight of turmeric rhizome.
\end{abstract}

Keywords: Manure; Mycorrhiza; Organic cultivation; Turmeric.

Cite this as: Samanhudi, Yunus, A., \& Pujiasmanto, B. 2018. Budidaya Organik Kunyit pada Kluster Biofarmaka Kabupaten Karanganyar. Caraka Tani: Journal of Sustainable Agriculture. 33(1), 34-41. doi:http://dx.doi.org/10.20961/carakatani.v33i1.19112

\section{PENDAHULUAN}

Potensi tanaman biofarmaka di Jawa Tengah cukup besar. Sentra tanaman biofarmaka seperti jahe, kencur, kunyit, dan temulawak tersebar di Semarang, Sukoharjo, Karanganyar, Purworejo, Boyolali, Banyumas, Magelang, Wonogiri, Rembang, dan Jepara. Di Jawa Tengah, produksi jahe mencapai 48.422 ton, kencur 8.691 ton, kunyit 27.612 ton, dan temulawak 6.928 ton (BPS, 2016), disamping itu masih dijumpai produk tanaman biofarmaka lain seperti adas, kapulogo, temukunci, purwoceng, dan lain-lain.

Berdasarkan data BPS (2016), produksi jahe, laos/lengkuas, kencur, dan kunyit di Kabupaten Karanganyar berturut-turut 3.473.892, 592.943, 140.467, dan $746.821 \mathrm{~kg}$. Wilayah tersebut merupakan salah satu sentra tanaman obat-obatan yang menyediakan bahan baku jamu tradisional untuk sekitar 66 perusahaan jamu skala kecil, menengah, dan besar. Sentra produksi jamu tradisional antara lain terdapat di Kecamatan Jaten, Jumapolo, dan Karangpandan. Pasar yang dilayani selain konsumen dalam negeri juga telah menembus pasar luar negeri seperti Brunei, Malaysia, Hongkong, Taiwan, Singapura, dan Timur Tengah.

Seiring dengan semakin besar perkembangan industri obat tradisional, produksi biofarmaka beberapa sentra tanaman obat termasuk Karanganyar belum mencukupi permintaan. Permintaan belum terpenuhi disebabkan pasar belum berkembang dan keengganan petani untuk menjual dalam bentuk produk siap pakai. Kenyataan di lapangan menunjukkan bahwa agribisnis biofarmaka tidak berkembang dengan baik dan merata di seluruh Indonesia, karena petani dan pelaku usaha kurang memahami kebutuhan pasar domestik dan ekspor yang menginginkan produk siap pakai. 
Penambahan bahan organik ke dalam tanah juga dapat meningkatkan perkembangan mikroorganisme tanah, karena pasokan karbon sebagai energi untuk pengembangan aktivitas mikroorganisme di tanah (Sari et al., 2015). Mikoriza juga meningkatkan sifat fisiologis penyerapan pada daerah permukaan dari sistem perakaran (Sivagurunathan et al., 2014). Dewanto et al. (2013) menambahkan bahwa pupuk kandang mengandung nutrisi nitrogen yang sangat besar bagi tanaman untuk pertumbuhan dan perkembangan, antara lain dapat menyebabkan daun lebih segar dan banyak mengandung klorofil yang memiliki peran sangat penting dalam proses fotosintesis dan meningkatkan kandungan nutrisi tanah.

Salah satu nutrisi yang diserap oleh tanaman untuk mendukung pertumbuhannya adalah unsur $\mathrm{P}$ (fosfor). Gyamfi et al. (2016) menyatakan bahwa fosfor $(\mathrm{P})$ merupakan nutrisi penting dan strategis untuk tanaman. Rivana et al. (2016) menambahkan bahwa fosfor juga disebut sumber kehidupan pada tumbuhan karena secara langsung terlibat dalam hampir semua proses kehidupan. Fosfor adalah komponen dari setiap sel hidup dan pada umumnya terdapat lebih banyak pada biji dan titik tumbuh.

Mikoriza meningkatkan toleransi tanaman terhadap berbagai tekanan termasuk nutrisi, kekeringan, keracunan logam, salinitas, dan semua patogen yang dapat mempengaruhi tanaman di tanah yang terkontaminasi atau tercemar (Chandra et al., 2014). Mikoriza memiliki peran protektif bagi tanaman inang dalam proses imobilisasi kontaminan tanah. Oleh karena itu, mikoriza memainkan peran penting dalam air limbah yang terkontaminasi dalam hal fitoremediasi logam berat (Amri, 2013).

Jha dan Kumar (2011) menjelaskan bahwa manfaat mikoriza untuk tanaman telah dijelaskan dengan baik dan termasuk penyerapan nutrisi yang efisien, terutama fosfor, peningkatan resistensi terhadap cekaman kekeringan, dan perlindungan langsung dan tidak langsung terhadap beberapa patogen. Mikoriza juga terlibat di semua ekosistem alam di sebagian besar zona iklim di seluruh dunia (Prsanthi et al., 2016). Jalavander dan Mamatha (2015) menyatakan bahwa asosiasi mikoriza terjadi di hampir semua spesies tanaman seperti kacang-kacangan, sereal, tanaman hijauan, tanaman hutan, tanaman perkebunan, dan tanaman obat.
Upaya meningkatkan produksi membutuhkan strategi yang terkait dengan teknik budidaya, pengolahan pasca panen, konservasi, dan riset pengembangan guna menjamin pengembangan dan keberlanjutan produksi. Strategi tersebut harus mengakomodasikan kepentingan ekonomi (produksi), konservasi, dan peningkatan kapasitas masyarakat.

\section{METODE PENELITIAN}

Penelitian dilaksanakan di Desa Sambirejo, Kecamatan Jumantono, Kabupaten Karanganyar pada bulan Maret sampai dengan bulan Oktober 2016. Percobaan terdiri atas dua faktor perlakuan dengan 16 kombinasi perlakuan dan masingmasing diulang sebanyak 5 kali. Faktor pertama berupa media tanam, terdiri atas 4 macam (tanah, tanah + pupuk kandang ayam, tanah + pupuk kandang kambing, dan tanah + pupuk kandang sapi). Faktor kedua berupa pemberian Cendawan Mikoriza Arbuskula (CMA), terdiri atas 4 taraf (tanpa CMA, 5, 10, dan $15 \mathrm{~g} /$ tanaman). Pengamatan dilakukan terhadap tinggi tanaman, jumlah daun, jumlah anakan, berat segar tanaman, berat kering tanaman, dan berat segar rimpang. Data hasil pengamatan dianalisis menggunakan analisis ragam (Anova) dan dilanjutkan dengan uji jarak berganda Duncan (DMRT) pada tingkat kepercayaan $95 \%$.

\section{HASIL DAN PEMBAHASAN}

\section{Tinggi Tanaman}

Pemberian beberapa jenis pupuk kandang dapat memberikan pengaruh terhadap tinggi tanaman kunyit (Tabel 1), demikian pula pemberian CMA (Tabel 2). Tabel 1 menunjukkan bahwa pemberian pupuk kandang meningkatkan tinggi tanaman kunyit, dibandingkan dengan tanpa pemberian pupuk kandang. Diantara pupuk kandang ayam, kandang kambing, kandang sapi berpengaruh tidak berbeda nyata. Pupuk kandang sangat dibutuhkan dalam pertumbuhan tanaman kunyit, adanya pupuk kandang mampu meningkatkan kesuburan tanah, meningkatkan unsur hara dan bahan organik tanah, mampu memperbaiki struktur tanah dan mikroorganisme dalam tanah (Mimbar, 2001). Pemberian pupuk kandang mempengaruhi tinggi tanaman, diameter batang, dan jumlah daun bibit abaca. Pemberian pupuk kandang $20 \mathrm{t} / \mathrm{ha}$ memberikan hasil yang lebih tinggi pada 14 MST (Musliha, 2003). 
Tabel 1. Pengaruh pemberian berbagai jenis pupuk kandang terhadap tinggi tanaman

\begin{tabular}{lc}
\hline Macam pupuk & Tinggi tanaman $(\mathrm{cm})$ \\
\hline Tanpa pupuk & $88,48 \mathrm{a}$ \\
Kandang ayam & $105,20 \mathrm{~b}$ \\
Kandang kambing & $104,36 \mathrm{~b}$ \\
Kandang sapi & $100,88 \mathrm{~b}$ \\
\hline
\end{tabular}

Keterangan: Angka yang diikuti huruf sama menunjukkan tidak berbeda nyata pada uji Duncan taraf 5\%.

Tabel 2. Pengaruh pemberian berbagai dosis CMA terhadap tinggi tanaman

\begin{tabular}{lc}
\hline Dosis CMA & Tinggi tanaman $(\mathrm{cm})$ \\
\hline Tanpa CMA & $90,10 \mathrm{a}$ \\
$5 \mathrm{~g} / \operatorname{tanaman}$ & $107,04 \mathrm{~b}$ \\
$10 \mathrm{~g} / \operatorname{tanaman}$ & $104,66 \mathrm{~b}$ \\
$15 \mathrm{~g} / \operatorname{tanaman}$ & $95,00 \mathrm{ab}$ \\
\hline
\end{tabular}

Keterangan: Angka yang diikuti huruf sama menunjukkan tidak berbeda nyata pada uji Duncan taraf 5\%.

Tabel 2 menunjukkan bahwa pemberian CMA mampu meningkatkan tinggi tanaman kunyit, jika dibandingkan tanpa pemberian mikoriza. Pemberian CMA dosis $5 \mathrm{~g} / \operatorname{tanaman}$ dan 10 g/tanaman berbeda nyata dengan tanpa pemberian CMA. Penggunaan CMA sebagai pupuk hayati sangat bermanfaat bagi tanaman dalam membantu penyerapan unsur hara. CMA mampu bersimbiosis dengan berbagai jenis tanaman dengan fungsi utama membantu tanaman dalam meningkatkan efisiensi penyerapan unsur hara, selain itu juga CMA dapat melestarikan sumberdaya lahan, secara fisik, kimia maupun biologis (Hartoyo et al., 2011).

Santosa et al. (2013) menyatakan bahwa penambahan $10 \mathrm{~g}$ mikoriza dapat meningkatkan tinggi biji jati putih (Gmelina arborea Roxb.). Mikoriza berperan dalam meningkatkan toleransi tanaman terhadap kondisi kritis tanah (Halim et al., 2015), sedangkan pupuk organik mengandung nutrisi dan sumber nitrogen untuk pertumbuhan tanaman (Karimuna et al., 2012). Karena nutrisi untuk tanaman tersedia dalam jumlah yang cukup, pertumbuhan dan perkembangan tanaman berjalan dengan baik. Aktivitas fisiologis tanaman akan berlangsung dengan baik tergantung pada ketersediaan nutrisi pada media dan jaringan tanaman, sehingga dapat menentukan pembagian proporsi asimilasi pada akar, batang, dan organ daun (Halim et al., 2016).

\section{Jumlah Daun}

Daun merupakan penerima cahaya dan alat fotosintesis. Hasil analisis ragam menunjukkan bahwa pemberian pupuk kandang berpengaruh nyata terhadap jumlah daun kunyit. Tabel 3 menunjukkan bahwa pemberian pupuk kandang ayam memberikan pengaruh berbeda sangat nyata terhadap jumlah daun dibandingkan dengan pupuk kandang lain (kambing dan sapi). Namun pemberian pupuk kandang kambing dan kandang sapi berbeda nyata dengan perlakuan tanpa menggunakan pupuk kandang. Bertambahnya jumlah daun berpengaruh terhadap peningkatan proses fotosintesis. Apabila proses fotosintesis meningkat maka fotosintat juga meningkat. Daun merupakan organ penting tanaman yang menggambarkan proses pertumbuhan tanaman dan termasuk organ produsen fotosintat utama (Pangaribuan, 2010). Pemberian pupuk kandang yang dikombinasikan dengan limbah kulit kopi masing-masing sebanyak $250 \mathrm{~g} /$ rumpun dapat meningkatkan jumlah anakan dan jumlah daun jahe putih (Gusmaini dan Trisilawati, 1980).

Tabel 3. Pengaruh pemberian berbagai jenis pupuk kandang terhadap jumlah daun tanaman

\begin{tabular}{lc}
\hline Macam pupuk & Jumlah daun \\
\hline Tanpa pupuk & $16,95 \mathrm{a}$ \\
Kandang ayam & $26,20 \mathrm{c}$ \\
Kandang kambing & $22,10 \mathrm{~b}$ \\
Kandang sapi & $23,45 \mathrm{~b}$ \\
\hline
\end{tabular}

Keterangan: Angka yang diikuti huruf sama menunjukkan tidak berbeda nyata pada uji Duncan taraf 5\%. 
Tabel 4. Pengaruh pemberian berbagai dosis CMA terhadap jumlah daun tanaman

\begin{tabular}{lc}
\hline Dosis CMA & Jumlah daun \\
\hline Tanpa CMA & $16,00 \mathrm{a}$ \\
$5 \mathrm{~g} /$ tanaman & $22,54 \mathrm{~b}$ \\
$10 \mathrm{~g} / \tan a m a n$ & $18,00 \mathrm{ab}$ \\
$15 \mathrm{~g} /$ tanaman & $23,11 \mathrm{~b}$ \\
\hline
\end{tabular}

Keterangan: Angka yang diikuti huruf sama menunjukkan tidak berbeda nyata pada uji Duncan taraf 5\%.

Tabel 4 menunjukkan bahwa pemberian CMA berpengaruh nyata terhadap jumlah daun. Dosis CMA $5 \mathrm{~g} / \operatorname{tanaman}$ dan $15 \mathrm{~g} /$ tanaman memberikan pengaruh nyata dalam pertumbuhan jumlah daun dibandingkan dengan tanpa CMA. Jumlah daun pada kunyit berpengaruh pada banyaknya cahaya yang diterima dan diserap tanaman untuk proses fotosintesis. Proses fotosintesis menghasilkan fotosintat yang digunakan untuk perkembangan dan pertumbuhan tanaman.

\section{Jumlah Anakan}

Pemberian pupuk kandang berpengaruh positif dalam pertumbuhan kunyit. Pemberian pupuk kandang merupakan input yang dianjurkan dalam pertanian organik. Pupuk kandang mampu menyediakan berbagai unsur hara yang dibutuhkan tanaman dalam pertumbuhan dan perkembangan, termasuk pertumbuhan jumlah anakan pada kunyit.

Tabel 5 hasil analisis ragam menunjukkan bahwa penggunaan pupuk kandang ayam berbeda sangat nyata dibandingkan dengan pupuk kandang kambing dan sapi. Penggunaan pupuk kandang ayam menghasilkan anakan yang lebih tinggi daripada pupuk kandang kambing dan sapi. Namun demikian penggunaan pupuk kandang kambing dan kandang sapi berpengaruh nyata dibandingkan dengan tanpa pemberian pupuk kandang. Pupuk kandang merupakan bahan organik yang mampu memperbaiki kesuburan tanah. Aplikasi berbagai kombinasi bahan organik seperti pupuk kandang, kulit kopi dan sekam pada jahe di rumah kaca memberikan respon yang positif terutama terhadap jumlah anakan (Sudiarto dan Gusmaini, 2004).

Tabel 5. Pengaruh pemberian berbagai jenis pupuk kandang terhadap jumlah anakan tanaman

\begin{tabular}{lc}
\hline Macam pupuk & Jumlah anakan \\
\hline Tanpa pupuk & $5,65 \mathrm{a}$ \\
Kandang ayam & $10,47 \mathrm{c}$ \\
Kandang kambing & $7,99 \mathrm{~b}$ \\
Kandang sapi & $8,80 \mathrm{~b}$ \\
\hline
\end{tabular}

Keterangan: Angka yang diikuti huruf sama menunjukkan tidak berbeda nyata pada uji Duncan taraf 5\%.

Tabel 6. Pengaruh pemberian berbagai dosis CMA terhadap jumlah anakan tanaman

\begin{tabular}{lc}
\hline Dosis CMA & Jumlah anakan \\
\hline Tanpa CMA & $5,85 \mathrm{a}$ \\
$5 \mathrm{~g} /$ tanaman & $9,48 \mathrm{~b}$ \\
$10 \mathrm{~g} /$ tanaman & $10,95 \mathrm{c}$ \\
$15 \mathrm{~g} /$ tanaman & $8,72 \mathrm{~b}$ \\
\hline
\end{tabular}

Keterangan: Angka yang diikuti huruf sama menunjukkan tidak berbeda nyata pada uji Duncan taraf 5\%.

Tabel 6 menunjukkan bahwa pemberian CMA dengan dosis $10 \mathrm{~g} /$ tanaman memberikan hasil yang berbeda sangat nyata dibandingkan dengan dosis CMA $5 \mathrm{~g} /$ tanaman dan $15 \mathrm{~g} /$ tanaman. Tetapi pada umumnya pemberian mikoriza mampu meningkatkan pertumbuhan tanaman kunyit.

Penambahan CMA dan pupuk kandang membantu penambahan anakan kunyit. Pupuk kandang berfungsi sebagai penyedia unsur hara makro dan mikro, sedangkan CMA membantu tanaman dalam penyerapan unsur hara.

\section{Berat Segar Tanaman}

Berat segar tanaman merupakan hasil dari metabolisme tanaman yang dipengaruhi unsur hara dan kandungan air sel-sel jaringan tanaman. Tabel 7 menunjukkan bahwa analisis ragam tidak berbeda nyata antara pemeberian pupuk kandang ayam, kandang kambing, kandang sapi, namun 
berbeda nyata terhadap perlakuan tanpa pemberian pupuk kandang. Penggunaan pupuk kandang terbukti mampu meningkatkan berat segar tanaman. Unsur nitrogen yang terkandung dalam pupuk kandang diperlukan tanaman untuk pertumbuhan vegetatif. Pada saat pertumbuhan vegetatif aktif, fotosintat akan digunakan untuk pertumbuhan dan perkembangan daun, batang, dan akar, sehingga berpengaruh terhadap berat segar tanaman.

Tabel 7. Pengaruh pemberian berbagai jenis pupuk kandang terhadap berat segar tanaman

\begin{tabular}{lc}
\hline Macam pupuk & Berat segar tanaman $(\mathrm{g})$ \\
\hline Tanpa pupuk & $212,04 \mathrm{a}$ \\
Kandang ayam & $587,20 \mathrm{~b}$ \\
Kandang kambing & $526,48 \mathrm{~b}$ \\
Kandang sapi & $540,44 \mathrm{~b}$ \\
\hline
\end{tabular}

Keterangan: Angka yang diikuti huruf sama menunjukkan tidak berbeda nyata pada uji Duncan taraf 5\%.

Tabel 8. Pengaruh pemberian berbagai dosis CMA terhadap berat segar tanaman

\begin{tabular}{lc}
\hline Dosis CMA & Berat segar tanaman $(\mathrm{g})$ \\
\hline Tanpa CMA & $232,72 \mathrm{a}$ \\
$5 \mathrm{~g} /$ tanaman & $520,25 \mathrm{~b}$ \\
$10 \mathrm{~g} /$ tanaman & $549,35 \mathrm{~b}$ \\
$15 \mathrm{~g} /$ tanaman & $539,00 \mathrm{~b}$ \\
\hline
\end{tabular}

Keterangan: Angka yang diikuti huruf sama menunjukkan tidak berbeda nyata pada uji Duncan taraf 5\%.

Sementara itu pada Tabel 8 dapat dilihat bahwa pemberian CMA tidak berbeda nyata antar berbagai perlakuan CMA. Hal ini diduga bahwa pemberian pupuk kandang sudah mampu meningkatkan pertumbuhan tanaman sehingga pemberian CMA dengan berbagai dosis tidak berpengaruh nyata. Namun hasil analisis ragam berbeda nyata antara perlakuan CMA dengan perlakuan tanpa menggunakan CMA.

\section{Berat Kering Tanaman}

Berat kering tanaman merupakan hasil dari fotosintesis. Penambahan pupuk kandang mampu meningkatkan berat segar tanaman, sehingga berat kering tanaman juga meningkat. Tabel 9 menunjukkan bahwa pemberian pupuk kandang ayam, kandang kambing, dan kandang sapi tidak berbeda nyata antara perlakuan, namun berbeda nyata terhadap perlakuan tanpa menggunakan pupuk kandang. Pemberian pupuk kandang juga bertujuan untuk memperbaiki struktur tanah yang rusak sehingga tanah menjadi gembur serta menambah unsur hara dalam tanah, terutama unsur hara makro untuk mencapai pertumbuhan tanaman yang optimum (Simandjuntak dan Waluyo, 1982).

Tabel 9. Pengaruh pemberian berbagai jenis pupuk kandang terhadap berat kering tanaman

\begin{tabular}{lc}
\hline Macam pupuk & Berat kering tanaman $(\mathrm{g})$ \\
\hline Tanpa pupuk & $42,00 \mathrm{a}$ \\
Kandang ayam & $82,40 \mathrm{~b}$ \\
Kandang kambing & $84,26 \mathrm{~b}$ \\
Kandang sapi & $77,14 \mathrm{~b}$ \\
\hline
\end{tabular}

Keterangan: Angka yang diikuti huruf sama menunjukkan tidak berbeda nyata pada uji Duncan taraf 5\%.

Tabel 10. Pengaruh pemberian berbagai dosis CMA terhadap berat kering tanaman

\begin{tabular}{lc}
\hline Dosis CMA & Berat kering tanaman $(\mathrm{g})$ \\
\hline Tanpa CMA & $48,00 \mathrm{a}$ \\
$5 \mathrm{~g} / \mathrm{tanaman}$ & $88,05 \mathrm{~b}$ \\
$10 \mathrm{~g} / \operatorname{tanaman}$ & $86,18 \mathrm{~b}$ \\
$15 \mathrm{~g} / \tan a m a n$ & $82,13 \mathrm{~b}$ \\
\hline
\end{tabular}

Keterangan: Angka yang diikuti huruf sama menunjukkan tidak berbeda nyata pada uji Duncan taraf 5\%. 
Tabel 10 menunjukkan pemberian berbagai macam konsentrasi CMA tidak berbeda nyata antara masing-masing konsentrasi, namun berbeda nyata terhadap perlakuan tanpa menggunakan CMA. CMA merupakan salah satu agen hayati yang mampu membantu penyerapan unsur hara terutama fosfor.

Menurut Choirina et al. (2013), berat kering tanaman merupakan indikator pertumbuhan tanaman yang dapat diukur secara terpisah berdasarkan bagian tanaman termasuk berat kering akar dan berat kering brangkasan. Berat kering tanaman dapat ditentukan dengan menimbang berat kering akar dan sisa tanaman.

\section{Berat Segar Rimpang}

Penggunaan pupuk kandang dan mikoriza secara umum mampu meningkatkan berat segar rimpang kunyit. Tabel 11 menunjukkan bahwa penggunaan pupuk kandang ayam memberikan pengaruh berbeda sangat nyata terhadap berat segar rimpang dibandingkan dengan penggunaan pupuk kandang yang lain (kambing dan sapi). Namun dengan pemberian pupuk kandang kambing dan kandang sapi berpengaruh berbeda nyata terhadap perlakuan tanpa menggunakan pupuk kandang.

Tabel 11. Pengaruh pemberian berbagai jenis pupuk kandang terhadap berat segar rimpang tanaman

\begin{tabular}{lc}
\hline Macam pupuk & Berat segar rimpang $(\mathrm{g})$ \\
\hline Tanpa pupuk & $200,40 \mathrm{a}$ \\
Kandang ayam & $410,23 \mathrm{c}$ \\
Kandang kambing & $345,00 \mathrm{~b}$ \\
Kandang sapi & $340,08 \mathrm{~b}$ \\
\hline
\end{tabular}

Keterangan: Angka yang diikuti huruf sama menunjukkan tidak berbeda nyata pada uji Duncan taraf 5\%.

Tabel 12. Pengaruh pemberian berbagai dosis CMA terhadap berat segar rimpang tanaman

\begin{tabular}{lc}
\hline Dosis CMA & Berat segar rimpang $(\mathrm{g})$ \\
\hline Tanpa CMA & $208,44 \mathrm{a}$ \\
$5 \mathrm{~g} /$ tanaman & $410,22 \mathrm{~b}$ \\
$10 \mathrm{~g} / \mathrm{tanaman}$ & $395,00 \mathrm{~b}$ \\
$15 \mathrm{~g} /$ tanaman & $375,05 \mathrm{~b}$
\end{tabular}

Keterangan: Angka yang diikuti huruf sama menunjukkan tidak berbeda nyata pada uji Duncan taraf 5\%.

Perlakuan pupuk kandang ayam menunjukkan hasil rimpang kunyit yang tertinggi dibandingkan pupuk kandang lain (kambing dan sapi). Hal ini diduga bahwa kandungan hara pada pupuk kandang ayam relatif lebih tinggi, karena bagian cair (urine) tercampur dengan bagian padat (Soegianto et al., 2002). Selain itu dekomposisi unsur hara juga mempengaruhi hara yang tersedia. Proses dekomposisi dipengaruhi sifat dari bahan organik tersebut. Kecepatan dalam merombak bahan organik berbeda sesuai dengan komponen utama penyusunnya. Pupuk kandang asal ternak kecil seperti ayam dan kambing akan berbeda komposisi unsur haranya dibandingkan dengan ternak besar seperti sapi dan kuda (Hanafiah, 2005).

Tabel 12 menunjukkan bahwa perlakuan berbagai konsentrasi CMA mampu meningkatkan hasil rimpang kunyit, dibandingkan dengan perlakuan tanpa pemberian CMA. Penelitian vanili dengan umur 18 MST menunjukkan bahwa inokulasi Mikoriza Arbuskula berpengaruh positif terhadap peningkatan indeks luas daun, bobot kering akar, batang dan daun, serta bobot kering biomassa pada dua klon vanili (Firman, 2008).

\section{KESIMPULAN}

Pupuk kandang ayam berpengaruh terhadap jumlah daun, jumlah anakan, dan berat segar rimpang kunyit. Pupuk kandang (ayam, kambing, dan sapi) mampu meningkatkan pertumbuhan tanaman yang meliputi tinggi tanaman, jumlah daun, jumlah anakan, berat segar tanaman, berat kering tanaman, dan berat segar rimpang. Dosis mikoriza $10 \mathrm{~g} /$ tanaman mampu meningkatkan jumlah anakan pada kunyit. Pemberian mikoriza pada berbagai dosis $(5,10$, dan $15 \mathrm{~g} /$ tanaman $)$ dapat meningkatkan tinggi tanaman, jumlah daun, jumlah anakan, dan berat segar rimpang kunyit. 


\section{ACKNOWLEDGEMENT}

Penulis mengucapkan terima kasih kepada Ketua Lembaga Penelitian dan Pengabdian kepada Masyarakat Universitas Sebelas Maret Surakarta, yang telah memfasilitasi kegiatan ini melalui Skim Iptek bagi Masyarakat (IbM) Dana PNBP UNS Tahun Anggaran 2016.

\section{DAFTAR PUSTAKA}

Amri, S.M. 2013. The functional roles of arbuscular mycorrhizal fungi in improving growth and tolerance of Vicia faba plants grown in wastewater contaminated soil. $J$. Microbiology Research. 7(35), 4435-4442.

Badan Pusat Statistik [BPS]. 2016. Luas panen dan produksi tanaman biofarmaka menurut kabupaten/kota di Jawa Tengah 2016.

Chandra, D., Sharma, G.D., \& Jha, D.K. 2014. Isolation and identification of some arbuscular mycorrhiza (AM) fungi for phytoremediation in soil contaminated with paper mill effluent. J. Current Microbiology and Applied Sciences. 3(6), 527-539.

Choirina, Y., Sudadi, \& Widijanto, H. 2013. The effect of bio-natural fertilizer on phosphorus absorption and peanut growth in alfisol, entisol, and vertisol soils. Sains Tanah Journal of Soil Science and Agroclimatology. 10(2), 113-121.

Dewanto, F.G., Londok, J.J.M.R., \& Tuturoong, R.A.V. 2013. The influence of inorganic and organic fertilization on corn crop production as feed source. J. Zootek. 32(5), 1-8.

Firman, C. 2008. Teknik inokulasi mikoriza arbuskula pada bibit vanili. Buletin Teknik Pertanian. 13(2), 47-50.

Gusmaini \& Trisilawati, O. 1980. Pertumbuhan dan produksi jahe muda pada media humus dan pupuk kandang. Jurnal Penelitian Tanaman Industri. 4(2), 42-48.

Gyamfi, J.J.A., Goh, K.M., \& Nguyen, M.L. 2016. An overview of phosphorus in the soil plant system agroecosystems and the enviroment. Vienna: International Atomic Energy Agency. 2-20p.

Halim., Arma, M.J., Karimuna, L., Rembon, F.S., \& Resman. 2016. Effect of mycorrhiza fungi propagules and bokashi fertilizer combination to weed density, growth and yield of maize (Zea Mays L.) on marginal dry land in regency of Kendari, Indonesia. Int $J$ Development Research. 6(9), 9568-9575.

Halim., Arma, M.J., Rembon, F.S., \& Resman. 2015. Impact of mycorrhiza fungi from grassland rhizosphere and liquid organic fertilizer to the growth and yield of sweet corn on ultisol in South Konawe, Indonesia. $J$. Agriculture, Forestry and Fisheries. 4(5), 209215.

Hanafiah, K.A. 2005. Dasar-dasar Ilmu Tanah. Penerbit PT Rajagrafindo Persada.

Hartoyo, B., Ghulamadhi, M., Darusman, L.K., Aziz, S.A., \& Mansur, I. 2011. Keanekaragaman fungi mikoriza arbuskula (FMA) pada rizozfer tanaman pegagan (Centella asiatica (L.) Urban). Jurnal Littri. 17(1), 32-40.

Jalavander, V.. \& Mamatha, M. 2015. Occurrence and assesment of vesicular arbuscular mycorrhizal fungi in some medicinal plants of apocyanaceae family. J. Global Biosciences. 4(5), 2239-2243.

Jha, S.K. \& Kumar, N. 2011. Potential of mycorrhizal fungi in ecosystem: a review. Int. J. Research in Botany. 1(1), 1-7.

Karimuna, L., Leomo, S., \& Indriyani, L. 2012. Improvement of maize and peanut production in intercropping system throught the application of organic fertilizer and mulch in ultisol soil. J. Nat Sci Special Issue on Agricultural \& Natural Resources. (1), 387394.

Mimbar, S.M. 2001. Pengaruh pupuk kandang terhadap pertumbuhan dan hasil panen tiga varietas kacang hijau. AGRIVITA, Journal of Agricultural Science. 18(2), 51-56.

Musliha, L. 2003. Teknik percobaan takaran pupuk kandang pada pembibitan abaca. Bulletin Teknik Pertanian. 8(1), 37-38.

Pangaribuan, H.D. 2010. Analisis pertumbuhan tomat pada berbagai jenis pupuk kandang. Prosiding Seminar Nasional Sains dan Teknologi-III. p 149-155.

Prsanthi, S., Jalander, V., \& Mamatha, M. 2016. The vesicular arbuscular mycorrhizal 
associations with two medicinal plant species in Telangana University Campus, Nizamabad (T.S.), India. J. Current Research in Biosciences and Plant Biology. 3(1), 62-65.

Rivana, E., Indriani, N.P., \& Khairani, L. 2016. Effect of phosphorus fertilization and inoculation of arbuscular mycorrhizal fungi (AMF) on sorghum plant growth and production (Sorghum bicolor L.). J. Animal Science. 16(1), 46-53.

Santosa, C.A., Harwati, T., \& Siswandi. 2013. The influence of arbuscular mycorrhiza and organic fertilizer on the growth of white teak seedlings (Gmelina arborea Roxb.). $J$. Agricultural Innovation. 12(2), 53-66.

Sari, A.D., Hariyono, D., \& Sumarni, T. 2015. Influence of manure and arbuscular mycorrhizal fungi (cma) on growth and results of corn plant (Zea mays L.). J. A Crop Production. 3(6), 450-456.
Simandjuntak, A.K. \& Waluyo, D. 1982. Cacing Tanah, Budidaya dan Pemanfaatannya. Jakarta: Penebar Swadaya.

Sivagurunathan, P., Sathiyamoorthy, M., \& Sivasubramani, K. 2014. Effect of mycorrhizal fungi on growth of Zea mays L. plants. Int. J. Advanced Research in Biological Sciences. 1(1), 137-148.

Soegianto, A., Hariyanto, A.E., \& Sugito, Y. 2002. Respon tanaman gandum (Triticum aestivum L.) galur Nias dan DWR 162 terhadap pemberian pupuk kandang ayam. AGRIVITA, Journal of Agricultural Science. 24(1), 30-36.

Sudiarto \& Gusmaini. 2004. Pemanfaatan organik bahan insitu untuk efisiensi budi daya jahe yang berkelanjutan. Jurnal Litbang Pertanian. 23(2), 37-45. 